\title{
Genetic differences for behaviour in juveniles from two strains of brown trout suggest an effect of domestication history
}

\author{
David Benhaïm $^{\mathrm{a}, *}$, René Guyomard ${ }^{\mathrm{b}}$, Béatrice Chatain $^{\mathrm{c}}$, Edwige Quillet $^{\mathrm{b}}$, Marie-Laure Bégout ${ }^{\mathrm{d}}$
}

\begin{abstract}
a LERMA, INTECHMER/CNAM, BP 324, 50103 Cherbourg cedex, France
b INRA, UMR 1313 Génétique Animale et Biologie Intégrative, 78350 Jouy-en-Josas, France

${ }^{\mathrm{C}}$ Ifremer, Station Expérimentale d'Aquaculture, Laboratoire de Recherche Piscicole de Méditerranée, Chemin de Maguelone, 34250 Palavas-Les-Flots, France

d Ifremer, Laboratoire Ressources Halieutiques de La Rochelle, Place Gaby Coll, BP 7, 17137 L'Houmeau, France
\end{abstract} *: Corresponding author : David Benhaïm, tel.: +3302338873 38 ; fax: +3302338873 39 ;
email address : $\underline{\text { david.benhaim@cnam.fr }}$

\begin{abstract}
:
Because captivity constitutes a drastic environmental change, domestication is expected to induce a rapid genetic selection for behavioural traits. In this study, we searched for genetic differences in behaviour among brown trout juveniles from two strains differing for their domestication history, i.e. an almost pure native wild Mediterranean population (W) and an Atlantic domesticated strain (D). In order to assess pure genetic differences among strains, males from the two origins were mated with Mediterranean females to produce two experimental crosses (WW and WD). The swimming activity characteristics of individual WW and WD juveniles were compared before and after the application of a stress (light switched off suddenly, followed by a 5-min period of darkness). For each of the fish observed, mating type origin (WW or WD) was unambiguously reassigned by genotyping. Behavioural responses differed between WD and WW fish. Angular velocity and the time spent immobile were greater for WW fish both before and after the short period of darkness, indicating higher reactivity. Once the light had been turned on again, mean velocity and total distance travelled were higher in WD than in WW fish. WD fish tended to recover levels of swimming activity higher than those before the dark period. This study therefore demonstrates an impact of genetic origin and domestication on swimming activity repertoire (higher reactivity in WW fish), a behavioural trait of particular importance for individual ecological performance. Owing to the contrasted domestication history of the two strains used in the comparison, we assume that the domestication level largely contributes to the behavioural changes observed.
\end{abstract}

Keywords: Domestication ; Genotyping ; Microsatellite ; Swimming activity ; Restocking 


\section{Introduction}

Domestication is the process by which a population of individuals becomes adapted to humans and to the captive environment, through the recurrence of environmentally induced developmental events in each generation and genetic changes occurring over generations (Price, 1999). These changes involve both deliberate and inadvertent selection, together with random genetic changes known as genetic drift, in which genetic variation is lost due to stochastic changes in allelic frequencies over several generations (Crow and Kimura, 1970). According to Denis (2004), domestication can best be described as a continuum of genetic transformations over generations constituting a general progression from the wild state to a state of genetic adaptation to captivity. For most farmed animals, essentially large terrestrial herbivorous and omnivorous mammals, domestication began 10500 years ago (Diamond, 2002). By contrast, the domestication of $97 \%$ of cultured fish species did not begin until the start of the $20^{\text {th }}$ century (Duarte et al., 2007). Farmed fish are therefore unlikely to differ markedly from the corresponding wild ancestral forms and only a few would be expected to be on the threshold of becoming domesticated (Balon, 2004). Nevertheless, domestication effects can already be observed in some fish, in some cases within as little as one or two generations of their removal from the natural environment (Dunham, 1996a). These modifications concern first morphological and behavioural characters (Bilio, 2007).

In fish, the coexistence of wild and domesticated stocks of the same species provides an opportunity to investigate the process and dynamics of the domestication process. A number of studies have been conducted to investigate differences between wild and domesticated fish.

Investigations of behavioural traits in wild and domesticated fish constitute an effective approach to studies of the domestication process, because these traits are likely to be among 
the first affected (Swain and Riddell, 1990; Ruzzante and Doyle, 1991; Ruzzante and Doyle, 1993; Price, 1999), in some cases within a generation of initial domestication (Vandeputte and Prunet, 2002; Bégout Anras and Lagardère, 2004; Huntingford, 2004). Antipredator behaviour, one of the most studied of these traits, has been shown to be very sensitive to artificial rearing (Johnsson and Abrahams, 1991; Berejikian, 1995; Dellefors and Johnsson, 1995; Johnson et al., 1996; Einum and Fleming, 1997; Fernö and Järvi, 1998; Johnsson et al., 2001), and swimming performances have been shown to be poorer in domestic stocks (Beamish, 1978). These differences between wild and cultured fish may be accounted for partly by differences in experience in the life histories of individual fish (Huntingford 2004). Farmed fish are faced with conditions that appear to be less challenging than natural habitats, with structurally simpler environments, a ready supply of food and an absence of predators. However, they also have to deal with high animal densities, space restrictions, artificial and uniform food and frequent handling (Fernö et al., 2007). Another way of studying the impact of domestication on fish is to investigate their behavioural responses to novel environments and/or challenging situations. Indeed, the most important effect of domestication on behaviour is a decrease in emotional reactivity or responsiveness to fear-evoking stimuli (i.e. environmental change, Price, 2002). Measurements of behavioural reactivity are thus sensitive indicators of the complex of biochemical and physiological changes occurring in response to stress (Schreck et al., 1997). For example, environments such as the light/dark plus maze, based on the tendency of fish to seek dark backgrounds (or to avoid light backgrounds) in unfamiliar environments, can be used to study such behaviour (Serra et al., 1999; Champagne et al., 2010; Gould, 2011; Steenbergen et al., 2011a). Another method involves the sudden exposure of fish to darkness, which has been used as an acute ecologically relevant challenge producing robust changes in locomotor activity in larval zebrafish (Ali et al., 2011). 
Brown trout, Salmo trutta L., is the most common salmonid in Europe and is of considerable socio-economic importance and heritage value because of its intraspecies diversity (Caudron et al., 2009). Two evolutionary lineages have been identified in France on the basis of allozymes, mtDNA and nuclear DNA markers: the Atlantic lineage (AL), which occurs in the rivers of the Atlantic catchment area, and the Mediterranean lineage, which occurs in the rivers of the Mediterranean basin (Guyomard, 1989; Bernatchez et al., 1992; Launey et al., 2003; Cortey et al., 2004).

An important issue in studies of the domestication of brown trout (and of many other fish) is the replacement of many natural populations by domesticated stocks through intensive stocking or escapees. For example, most of the native Mediterranean lineage in France has been replaced by domesticated stocks belonging to the Atlantic lineage (Krieg and Guyomard, 1985; Barbat-Leterrier et al., 1989; Guyomard, 1989; Beaudou et al., 1994; Largiadèr et al., 1996; Poteaux et al., 1998; Berrebi et al., 2000; Launey et al., 2003) and this is also probably true for most of the native Atlantic populations. Thus, in most comparisons of domestic and wild stocks, it is not possible to exclude the possibility that the two genotypes investigated originate from domesticated stocks and differ only in one of them having being released into the wild for a short period of time. This may bias the experiments carried out. Fortunately, remnant unstocked or almost unstocked native Mediterranean populations of brown trout have been identified (Caudron et al., 2011) and provide a suitable genetic source for studying the domestication process in this species. Furthermore, many studies of phenotypic differences between wild and domesticated stocks of fish species do not include the necessary fertilisation designs for separation of the effects of genetic and environmental factors. It is also important to take into account maternal effects, which contribute to phenotypic complexity for many traits, and may complicate attempts at 
117 phenotypic analysis (Bernardo, 1996). Maternal effects in fish are due to the energy reserves

118 within the yolk (reviewed by Love 1980), which depend on the reserves the female is able to

119 commit to oogenesis and oocyte maturation (Kerrigan, 1997). Many studies comparing wild

120 fish with those from hatcheries fail to recognise the influence of maternal effects on egg

121 quality, with repercussions for the survival and behaviour of the offspring (Huntingford

122 2004). Gene-environment interactions can also be limited by placing all the fish in the same

123 environment (Dupont-Nivet et al., 2008) or by using replicates to assess tank effects.

124

125 There have been few studies of the domestication process based on differences in behaviour 126 between wild and domesticated fish and an experimental design allowing the identification of

127 lineages and the control of environmental sources of variation. However, a recent study on 128 zebrafish, Danio rerio, confirmed the potential of such studies for the QTL mapping of 129 behavioural traits and for dissecting the consequences of selection during domestication 130 (Wright et al., 2006).

132 In this study, we assessed the genetic variation underlying differences in behavioural traits

133 between genetically differentiated populations of juvenile brown trout. This study is 134 innovative in its use of genotypes corresponding to well characterized stages of 135 domestication. In particular, we compared juveniles produced by mating females from a near136 pure Mediterranean population with males from the same population (WW) or with males 137 from an Atlantic domesticated strain (WD). The swimming activity characteristics of 138 individual WW and WD fish were compared before and after a short period of darkness, and 139 each of the fish studied was genotyped to check its origin.

\section{Materials and methods}




\subsection{Experimental animals and housing conditions}

In December 2006, an experimental captive population was founded with 11 females and 16 males (effective population size $=22.8$ ) caught in the Fier, a tributary of the Rhône inhabited by an almost pure Mediterranean population (Guyomard and Caudron, unpublished data). We checked that the parents had a Mediterranean genetic profile by genotyping with Str541 and Str591, two microsatellites that have proved useful for differentiating between Atlantic stock strains and Mediterranean populations (see Estoup et al., 2000 and Caudron et al., 2006, for details on the method). Fish were fertilised, hatched and reared to sexual maturity at La Puya fish farm (Annecy, Haute-Savoie, France).

In 2009, an experiment with a semi-factorial design was carried out with mature males and females of the Fier captive population and males from the INRA strain (INRA experimental fish-farm, Le Drennec, Finistère, France). We pooled the eggs from all females and divided them up into the same number of groups as individual males used. Each group of eggs was fertilized by an individual male. Fifteen minutes after fertilisation, all the eggs fertilised by males of the same origin were pooled and each pool was divided into two replicates (R1 and R2, Table 1). Eggs were incubated at temperatures of 6 to $10{ }^{\circ} \mathrm{C}$, in small stainless steel incubators, until the first feed, after which they were transferred to small concrete tanks until the end of the experiment. The fry were initially fed with zooplankton, which was gradually replaced with dry pellets. The fish were reared according to standard trout farming practice. The behavioural experiment was started 280 days after fertilisation of the eggs.

\subsection{Experimental set-up}

Observations were made in a specially modified dark room dedicated to this experiment at La Puya farm. The apparatus consisted of 12 transparent rectangular arenas $(24.5$ x 15 x 13.5 cm, Aquabox ${ }^{\circledR}$ 3, AQUA SCHWARZ GmbH, Göttingen, Germany), each filled with 1.5 L of 
water (the water used had characteristics identical to those of the water in the original tanks) giving a water depth of $7 \mathrm{~cm}$. The temperature and oxygen level were checked before and after the observations. Temperature was $11.6 \pm 0.6^{\circ} \mathrm{C}$ before and $12.8 \pm 0.3^{\circ} \mathrm{C}$ after the observations, whereas oxygen concentration was $7.4 \pm 0.2 \mathrm{mg} \mathrm{L}^{-1}$ before and $7.2 \pm 0.2 \mathrm{mg} \mathrm{L}^{-1}$

171 after the observations. Arenas were numbered from 1 to 12 and placed on a waterproof 172 infrared casing ( $1 \times 1 \mathrm{~m}$, Noldus, The Netherlands) to assist the recording of videos in total 173 darkness. A frame made of opaque white cardboard was placed against each arena, preventing visual interaction between fish. A camera (Imaging Source DMK 21AUO4) with a frame rate of $30 \mathrm{~Hz}$ and a resolution of $640 \times 480$ pixels was positioned $87 \mathrm{~cm}$ above the infrared casing. Three $120 \mathrm{~W}$ spot lights placed around the infrared casing were used to light the arenas indirectly. The light intensity measured at the surface of the water in each arena was 150 Lux. The spot lights were connected to a programmable timer, making it possible to turn the light on or off automatically at specific times.

\subsection{Experimental protocol}

182 Six WW (3 R1 and 3 R2) and six WD (3 R1 and 3 R2) fish were gently collected from the 183 tanks with a dip net and individually transferred into arenas in random order. Care was taken to select juveniles of the two origins that were visibly similar in size. The fish were allowed to acclimatise to the arenas for 5 minutes before the start of video recording. The arenas were filmed for $65 \mathrm{~min}$ : $30 \mathrm{~min}$ in the light, 5 min of darkness and then another 30 minutes in the

187 light. The light was turned off abruptly, resulting in sudden darkness, and then switched back 188 on, with the programmable timer. At the conclusion of each recording period, individuals were placed in 12 numbered 1-litre beakers. They were anaesthetised with 2-phenoxyethanol

$190\left(0.3 \mathrm{ml} \mathrm{L}^{-1}\right)$ for measurement (total body length, BL, to the nearest $\mathrm{mm}$ ) and weighing (BW, 
191 to the nearest mg). Thereafter, the anaesthetised fish were sacrificed by severance of the 192 spinal cord.

193

194 Fin clips were taken from each of the juveniles observed and stored in 95\% ethanol for 195 genotyping. DNA extraction and genotyping with Str541 and Str591 microsatellite markers 196 was performed as described by Caudron et al. (2006). We also took fin clips from each of the 197 males and females used to generate the juveniles studied.

198 This procedure was carried out eight times in all (i.e. $48 \mathrm{WW}$ and $48 \mathrm{WD}$ fish were observed 199 over two days).

200 The water in each arena was replaced, in its entirety, after each observation session.

201

202 2.4. Video analyses and behavioural variables

203 The video recordings were analyzed with EthoVision XT software (Noldus, The 204 Netherlands), which was used to track the swimming fish in each arena.

205 Each video recording was analysed in three sequences:

206 - L1: 30 minutes in the light.

207 - D: 5 minutes in the dark.

208 - L2: 30 minutes in the light.

209 For each sequence, the following variables of interest were used to characterise the swimming 210 behaviour of the fish:

211 - Distance moved: the distance travelled by the centre point of the subject between two 212 consecutive $\mathrm{X}-\mathrm{Y}$ coordinates acquired (Dtot in $\mathrm{mm}$ ), 
- Mean velocity: the distance moved by the centre point of the individual fish per unit time

215 between two consecutive $\mathrm{X}-\mathrm{Y}$ coordinates acquired expressed in body lengths per second 216 (Vel in $\left.\mathrm{BL} \mathrm{s}^{-1}\right)$,

217 - Time immobile: the total duration the fish displayed no movement (NotMov in second) with 218 a threshold of $1.7 \mathrm{~cm} \mathrm{~s}^{-1}$,

219 - The fish absolute angular velocity expressed in degrees per second (Vang in $\circ \mathrm{s}^{-1}$ ) was 220 calculated by the software as followed: $\operatorname{Vang}_{n}=\mathrm{RTA}_{\mathrm{n}} / \mathrm{t}_{\mathrm{n}}-\mathrm{t}_{\mathrm{n}-1}$, where $\mathrm{RTA} \mathrm{A}_{\mathrm{n}}$ is the relative turn 221 angle for sample $n$, and $t_{n}-t_{n-1}$ is the time difference between the current and previous 222 sample. Here, the rate of change in direction is unsigned. The turn angle is calculated as the 223 difference between two subsequent values for heading direction. This variable was an 224 indicator of the amount of turning per unit time and quantified the swimming path 225 complexity.

\subsection{Statistical analysis}

228 All variables were compared by parametric analysis of variance (ANOVA), after checking 229 that the normality and homoscedasticity requirements were met (Dagnélie, 1975). All 230 statistical analyses were conducted with Statistica 8 (Statsoft, USA) and, for all tests, $p<0.05$ was considered significant.

232 BL and BW were compared in a one-way analysis of variance, with Replicate (R1 and R2) as 233 the fixed factor, and then in a one-way analysis of variance with Origin (WW and WD) as the 234 fixed factor.

235 The regression between each swimming variable and either BL or BW was analysed, to check 236 for allometric relationships in fish of the two origins during each period (L1, D and L2).

237 The effects of fish size were resolved, by comparing all variables relating to swimming 238 activity in a repeated measures analysis of covariance after checking for parallelism 
239 (Dagnélie, 1975). Fish origin (WW and WD) was taken as a between-subject factor, Sequence 240 (L1, D and L2) as a within-subject factor and body size or body weight as a covariate. 241 Significant ANCOVA results were followed by a post-hoc multiple comparison test 242 (Newman-Keuls).

\section{Results}

\subsection{Biometry}

No significant differences in weight or size were found between replicates of the same origin and data were therefore pooled for further analyses. However, WD fish were significantly heavier and larger than WW fish $\left(1.54 \pm 0.52\right.$ and $1.19 \pm 0.55 \mathrm{~g}, \mathrm{~F}_{(1,94)}=9.8, P=0.002 ; 5.49$ \pm 0.63 and $5.08 \pm 0.70 \mathrm{~cm}, \mathrm{~F}_{(1,94)}=8.8, P=0.004$, respectively).

251

252

253

254

255

\subsection{Genotyping}

The INRA males had only Atlantic alleles (Str541*132, Str591*150 and *152), whereas the Fier males and females had only Mediterranean alleles (Str541*136, Str591*164, *166 and *170), with the exception of a single female with one Atlantic allele (Str541*132). The juveniles were therefore unambiguously reassigned to the WW or WD group by genotyping for these two markers. All the genotyping results were consistent with the expected genotypes of the fish analyzed.

\subsection{Swimming activity}

In most cases, correlations between swimming variables and BL or BW were weak and not significant. However, two significant correlations were identified in WW fish during L1: a correlation between Dtot and BL or BW $\left(r^{2}=0.22, P=0.001 ; r^{2}=0.18, P=0.003\right.$ respectively) and a correlation between NotMov and BL or BW $\left(\mathrm{r}^{2}=0.22, P=0.001\right.$ in both cases). Dtot tended to decrease with increasing BL or BW and NotMov tended to increase 
with increasing BL. There was also one significant correlation in WD fish, during L2, between Vang and BL $\left(r^{2}=0.1, P=0.03\right)$. Vang tended to increase with increasing BL.

The hypothesis of parallelism was verified for each of the variables studied. This involved that the slope of the regression line for swimming traits against fish size or fish weight did not differ significantly between fish of different origins. Similar results were obtained whether BL or BW was used as a covariate, so we present only the results obtained with BL below.

The difference in Vang between WW and WD was significant $\left(\mathrm{F}_{(3,85)}=10.9, P<0.001\right)$. Further, Newman-Keuls tests showed that Vang was higher in WW fish than in WD fish during L1 (but not significant: $P=0.06$, Figure 1$)$ and L2 $(P<0.001)$ but not during D $(P=$ 0.55), when Vang decreased in fish of both origins. The significant difference observed during L2 results from the combination of an increase in Vang during this period in WW fish and a tendency for Vang to decrease in WD over the same period (Figure 1). If we consider measurements taken every minute (Figure 2), Vang was always higher in WW fish than in WD fish during L1 and L2. During the dark phase (D), the two groups of fish reacted similarly, with an immediate decrease in Vang, which lasted from the beginning to the end of D; Vang continued to decrease during the first minute of L2 and then increased thereafter.

Dtot differed significantly between WW and WD fish $\left(\mathrm{F}_{(3,85)}=11.4, P<0.001\right)$. Further Newman-Keuls tests showed that the difference was significant only during L2 $(P<0.001)$. In WD fish, Dtot increased more strongly in L2 than in L1, whereas similar values were obtained for these two periods for WW fish (Figure 1).

Similarly, Vel differed significantly between WW and WD fish $\left(\mathrm{F}_{(3,85)}=11.9, P<0.001\right.$, Figure 1). As for Dtot, the difference was significant only during L2, when Vel increased in 
WD fish ( $P<0.001$, Figure 1$)$. If we consider measurements taken every minute (Figure 2),

294 the two groups of fish reacted similarly, with an immediate decrease in Vel at the beginning 295 of D, followed by an increase until the end of D; Vel then decreased again at the beginning of

296

297

298

299

300

301

302

303

304

305

306

307

L2. However, during L2, Vel fell to values lower than those for L1 in WW fish, whereas it remained higher than during L1 in WD fish.

Finally, NotMov differed significantly between WW and WD fish $\left(\mathrm{F}_{(3,85)}=13.9, \mathrm{P}<0.001\right)$. This difference was significant during L1 and L2 $(P=0.04$ and $P<0.001$, respectively, Figure 1), but not during $\mathrm{D}(\mathrm{P}=0.48)$. WD fish were immobile for $50.4 \pm 3.8 \%$ of the time during L1 and for $43.1 \pm 3.1$ of the time during L2, whereas WW fish were immobile for 60.5 $\pm 3.3 \%$ of the time during $\mathrm{L} 1$ and $61.6 \pm 2.7$ of the time during $\mathrm{L} 2$.

\section{Discussion}

In this study, we compared the swimming behaviour (in a challenging situation) of two groups of brown trout juveniles, the origin of which was clearly identified by genotyping. These two groups differed in terms of the domestication history of the male parents. The Atlantic INRA strain has a long history of domestication that largely predates the foundation of the strain (more than 10 generations), which itself originates from a mixture of domesticated stocks, whereas the Mediterranean La Puya strain has been in captivity for only one generation. Since the two groups differed only in terms of the genetic background of the male parents, the observed significant differences should provide an estimate of strictly paternal genetic effects (both additive and dominance effects) for the behavioural traits investigated. These genetic differences result from two sources of variation: 1) the two populations used initially originated from two different well differentiated lineages and 2) they also differ in terms of their domestication history. With the experimental design used, it 
was not possible to dissect the relative contributions of the two factors, but the nature of the

319 differences between the two genotypes strongly support the hypothesis, discussed below, that these differences partly reflect an impact of the domestication process on behavioural traits.

Growth performance is known to increase rapidly with the stage of domestication in fish (Gjedrem, 1979). The results obtained for the WW and WD groups were consistent with this observation. A substantial difference ( $20 \%$ ) was already evident 180 days after fertilisation (see table 1) and was maintained until sampling for the behavioural assay. Differences in growth and survival rate were repeatedly observed between French wild and domesticated brown trout populations at the advantage of the latter group (Guyomard, 1989, 1997). These studies also showed that reciprocal hybrids were intermediate between the two parental strains. The visual selection of juveniles was not sufficient to ensure that the WW and WD groups were homogeneous in terms of size and weight. However, we found that swimming activity was only weakly correlated with fish size or weight.

Significant differences were recorded between WD and WW fish for several behavioural traits. Angular velocity and time spent immobile were greater in WW than in WD fish, both before and after the light was turned off. Mean velocity and total distance travelled were higher in WD fish, particularly during the 30-minute period after the light was switched back on. These results reflect a lower swimming complexity in WD fish and a higher vigilance threshold (Bégout and Lagardère 2004) or stronger fear response (Arai et al., 2007) in WW

339 fish, regardless of the challenge period (initial introduction into the test tank, or after the 340 period of darkness). These findings are consistent with previous studies comparing wild341 caught and domesticated sea bass juveniles under similar conditions (Benhaïm et al., 2012b) and probably reflect an antipredator response that has already been shown to be eroded in several farmed species, including Atlantic salmon, Salmo salar (Einum and Fleming 1997), 
rainbow trout, Oncorhynchus mykiss (Johnsson and Abrahams 1991), brown trout, (Fernö and

345 Järvi 1998), and Atlantic cod, Gadus morhua (Nordeide and Svasand, 1990).

346 The observed differences are mostly accounted for by the inheritance of differentially selected 347 behavioural characters over several generations (Huntingford 2004). Indeed, during the 348 domestication process, the frequency distributions of various behavioural traits change, partly 349 because the fish selected from the source populations generally thrive in the predator-free and 350 food-rich hatcheries (Salvanes and Braithwaite, 2006).

352 The behavioural differences between WW and WD fish, which are likely to reflect only half 353 the genetic differences between the two strains, were quantitative rather than qualitative in 354 nature (see Price 2002), because both groups of fish reacted similarly to the two stimuli (light 355 off, light on). Indeed, the sudden onset of darkness triggered a decrease in mean velocity 356 rapidly followed by an increase, indicating avoidance of a potentially dangerous area and risk assessment (Millot et al., 2009). A similar decrease in locomotor activity following a sudden onset of darkness has been described in zebrafish, in which sudden changes in illumination 359 can temporarily override the activity levels set by the circadian clock (Steenbergen et al. 360 2011b). However, recovery differed between the two groups of fish: 30 minutes after the 361 second stimulation, WD fish had recovered higher levels of swimming activity, whereas the 362 level of swimming activity remained low in WW fish. Thus, WW fish remained fearful, as 363 reported for sea bass by Millot et al. (2009). Similarly, sudden exposure to darkness triggered 364 a decrease in angular velocity in both groups of fish. Thirty minutes after exposure to 365 darkness, only the WW fish displayed an increase in angular velocity, although values 366 remained lower than those before the first stimulation in both groups of fish. 
Clearly, these differences have implications for the management of aquaculture systems and 369 for the success of restocking programmes (Huntingford 2004). Indeed, it is increasingly recognized that restocking programmes often fail because of behavioural deficits in the

371 domesticated fish released (Olla et al., 1994; Brown and Laland, 2001; Brown, 2002; Huntingford, 2004), resulting in lower fitness in natural environments (Einum and Fleming, 1997; Fleming and Einum, 1997; Garant et al., 2003; McGinnity et al., 2003; Metcalfe et al., 2003). This is of particular importance in salmonids, given the long history of restocking and farming of this taxonomic group (Salvanes and Braithwaite 2006) and one should indeed favour fear related behavioural traits when doing restocking

This study constitutes one of the first attempts to demonstrate the existence of genetic difference for behavioural traits between populations with different domestication profiles. The behavioural traits identified here as relevant indicators of the domestication process in brown trout are probably also applicable to other fish species. The experimental set-up described here should be improved in several ways in future studies. One major improvement would involve the use of full 2x2 factorial designs comparing F2-F3 captive Mediterranean broodstocks with their wild source populations. This will make it possible to avoid bias due to geographic variation and to assess domestication effects only. Moreover, we would estimate the total differences between the two strains rather than the paternal effect only (corresponding to half the expected additive genetic variability between strains).

The experiment carried out here focused on the behavioural response to a physical stressor, but could be extended to other relevant traits such as early feeding behaviour, predator avoidance, physiological response to handling or crowding. It would be of particular interest in the perspective of understanding the genetic changes occurring in the course of the domestication process. Finally, we suggest that particular attention should be paid to 
determining how gene $\mathrm{x}$ environment interactions affect behavioural and physiological adaptation in fish (Johnsson et al. 2001).

\section{Acknowledgements}

We would like to thank Yves Josserand and Daniel Dizar from La Puya farm for providing the facilities and an excellent working environment for the completion of this work. This work was supported by the Groupement De Recherches INRA-Ifremer “AGPi” (Amélioration génétique pour une pisciculture durable). This study was conducted with the approval of the French Animal Care Committee under the terms of the official licence of M.L. Bégout (17010).

\section{References}

Ali, S., Champagne, D.L., Richardson, M.K., 2011. Behavioral profiling of zebrafish embryos exposed to a panel of 60 water-soluble compounds. Behav. Brain Res. 228, 272-283.

Arai, T., Tominaga, O., Seikai, T., Masuda, R., 2007. Observational learning improves predator avoidance in hatchery-reared Japanese flounder Paralichthys olivaceus juveniles. J. Sea Res. 58, 59-64.

Balon, E.K., 2004. About the oldest domesticates among fishes. J. Fish Biol. 65, 1-27.

Barbat-Leterrier, A., Guyomard, R., Krieg, F., 1989. Introgression between introduced domesticated strains and Mediterranean native populations of brown trout (Salmo trutta L.). Aquat. Living Resour. 2, 215-223.

Beamish, F.W., 1978. Swimming capacity. Book : Fish Physiology VII, Locomotion, 101-185.

Beaudou, D., Cattaneo-Berrebi, G., Berrebi, P., 1994. Impacts génétiques des repeuplements en truites communes (Salmo trutta L.) sur les populations en place; cas du bassin de l'Orb (Hérault). Bull. Fr. Peche Piscic. 332, 83-92.

Bégout Anras, M.-L., Lagardère, J.P., 2004. Measuring cultured fish swimming behaviour: first results on rainbow trout using acoustic telemetry in tanks. Aquaculture 240, 175-186. 
Benhaim, D., Péan, S., Lucas, G., Blanc, N., Chatain, B., Bégout, M.-L., 2012. Early life behavioural differences in wild caught and domesticated sea bass (Dicentrarchus labrax). Appl. Anim. Behav. 141, 79-90.

Berejikian, B.A., 1995. The effects of hatchery and wild ancestry and experience on the relative ability of steelhead trout fry (Oncorhynchus mykiss) to avoid a benthic predator. Can. J. Fish. Aquat. Sci. 52, 2476-2482.

Bernardo, J., 1996. Maternal effects in animal ecology. Am. Zool. 36, 83-105.

Bernatchez, L., Guyomard, R., Bonhomme, F., 1992. DNA sequence variation of the mitochondrial control region among geographically and morphologically remote European brown trout salmo trutta populations. Mol. Ecol. 1, 161-173.

Berrebi, P., Poteaux, C., Fissier, M., Cattaneo-Berrebi, G., 2000. Stoking impact and allozyme diversity in brown trout from Mediterranean southern France. J. Fish Biol. 56, 949-960.

Bilio, M., 2007. Controlled reproduction and domestication in aquaculture - the current state of the art, Part I-IV. Aquaculture Europe

Brown, C., 2002. Do female rainbowfish (Melanotaenia spp.) prefer to shoal with familiar individuals under predation pressure? J. Ethol. 20, 89-94.

Brown, C., Laland, K., 2001. Social learning and life skills training for hatchery reared fish. J. Fish Biol. 59, 471-493

Caudron, A., Champigneulle, A., Guyomard, R., 2006. Assessment of restocking as a strategy for rehabiliting a native population of brown trout (Salmo trutta) in a fast flowing mountain stream in the northern French Alps. J. Fish Biol. 69, 127139.

Caudron, A., Champigneulle, A., Guyomard, R., 2009. Evidence of two contrasting brown trout Salmo trutta populations spatially separated in the River Borne (France) and shift in management towards conservation of the native lineage. J. Fish Biol. 74, 1070-1085.

Caudron, A., Champigneulle, A., Guyomard, R., Largiadèr, C.R., 2011. Assessment of three strategies practiced by fishery managers for restoring native brown trout (Salmo trutta) populations in Northern French Alpine Streams. Ecol. Freshw. Fish. 20, 478-491.

Champagne, D.L., Hoefnagels, C.C.M., de Kloet, R.E., Richardson, M.K., 2010. Translating rodent behavioral repertoire to zebrafish (Danio rerio): Relevance for stress research. Behav. Brain Res. 214, 332-342. 
Cortey, M., Pla, C., Garcia-Marin, J., 2004. Historical biogeography of Mediterranean trout. Mol. Phylogenet. Evol. 33, 831-844.

Crow, J.F., Kimura, M., 1970. An introduction to population genetics theory. Harper and Row, New York.

Dagnélie, P., 1975. Théorie et méthodes statistiques. In : Applications agronomiques vol. 2, 463 pp. Presses Agronomiques de Gembloux, Gembloux.

Dellefors, C., Johnsson, J.I., 1995. Foraging under risk of predation in wild and hatchery-reared juvenile sea trout (Salmo trutta L.). Nord. J. Freshw. Res. 70, 31-37.

Denis, B., 2004. La domestication: un concept devenu pluriel. INRA Prod. Anim. 17, 161-166.

Diamond, J., 2002. Evolution, consequences and future of plant and animal domestication. Nature 418, 700-707.

Duarte, C.M., Marba, N., Holmer, M., 2007. ECOLOGY: Rapid Domestication of Marine Species. Science 316, 382-383.

Dunham, R.A., 1996a. Contribution of genetically improved aquatic organisms to global food security. International Conference on Sustainable Contribution of Fisheries to Food Security. Government of Japan and FAO, Rome, 150 pp.

Dupont-Nivet, M., Vandeputte, M., Vergnet, A., Merdy, O., Haffray, P., Chavanne, H., Chatain, B., 2008. Heritabilities and GxE interactions for growth in the European sea bass (Dicentrarchus labrax L.) using a marker-based pedigree. Aquaculture 275, 81-87.

Einum, S., Fleming, I.A., 1997. Genetic divergence and interactions in the wild among native, farmed and hybrid Atlantic salmon. J. Fish Biol. 50, 634-651.

Estoup, A., Largiadèr, C.R., Cornuet, J.M., Gharbi, K., Presa, P., Guyomard, R., 2000. Juxtaposed microsatellite systems as diagnostic markers for admixture: an empirical evaluation with brown trout (Salmo trutta) as model organism. Mol. Ecol. 9, 1873-1886.

Fernö, A., Huse, G., Jakobsen, P.J., Kristiansen, T.S., 2007. The Role of Fish Learning Skills in Fisheries and Aquaculture. Blackwell Publishing Ltd.

Fernö, A., Järvi, T., 1998. Domestication genetically alters the antipredator behaviour of anadromous brown trout (Salmo trutta)- a dummy predator experiment Nord. J. Freshw. Res. 74, 95-100 
Fleming, I.A., Einum, S., 1997. Experimental tests of genetic divergence of farmed from wild Atlantic salmon due to domestication. ICES J. Mar. Sci. 54, 10511063.

Garant, D., Fleming, I.A., Einum, S., Bernatchez, L., 2003. Alternative male life-history tactics as potential vehicles for speeding introgression of farm salmon traits into wild populations. Ecol. Lett. 6, 541-549.

Gjedrem, T., 1979. Selection for growth rate and domestication in Atlantic salmon. Z. Tierzuecht. Zuechtungsbiol. 96, 56-59.

Gould, G.G., 2011. Aquatic Light/Dark Plus Maze Novel Environment for Assessing Anxious Versus Exploratory Behavior in Zebrafish (Danio rerio) and Other Small Teleost Fish, pp. 99-108.

Guyomard, R., 1989. Gestion génétique des populations naturelles: l'exemple de la truite commune. Bull. Fr. Peche Piscic. 314, 136-145.

Guyomard, R., 1997. Conséquences génétiques des introductions d’espèces de poissons en l'absence d'isolement reproducteur : intérêt et limites d'une approche en milieu expérimental. Bull.Fr.Pêche Piscic. 344, 301-308.

Huntingford, F.A., 2004. Implications of domestication and rearing conditions for the behaviour of cultivated fish. J. Fish Biol. 65, 122-142.

Johnson, T.P., Bennett, A.F., McLister, J.D., 1996. Thermal dependence and acclimation of fast start locomotion and its physiological basis in rainbow trout (Oncorhynchus mykiss). Physiol. Zool. 69, 276-292.

Johnsson, J.I., Abrahams, M.V., 1991. Interbreeding with domestic strain increases foraging under threat of predation in juvenile steelhead trout (Oncorhynchus mykiss): an experimental study. Can. J. Fish. Aquat. Sci. 48, 243-247.

Johnsson, J.I., Höjesjö, J., Fleming, I.A., 2001. Behavioural and heart rate responses to predation risk in wild and domesticated Atlantic salmon. Can. J. Fish. Aquat. Sci. 58 788-794

Kerrigan, B., 1997. Variability in larval development of the tropical reef fish Pomacentrus amboinensis (Pomacentridae): the parental legacy. Mar. Biol. 127, 395-402.

Krieg, F., Guyomard, R., 1985. Population genetics of french brown trout (Salmo trutta L.): large geographical differentiation of wild populations and high similarity of domesticated stocks. Génétique Sélection Evolution 17, 225-242. 
Largiadèr, C.R., Scholl, A., Guyomard, R., 1996. The role of natural and artificial propagation on the genetic diversity of brown trout (Salmo trutta L.) of the upper Rhône drainage. In Conservation of Endangered Freshwater Fish in Europe (Kirchhofer, A. \& Hefti, d., eds), pp. 181-197. Basel: Birkhauser Verlag. Launey, S., Krieg, F., Champigneulle, A., Guyomard, R., 2003. Ecotypes sympatriques migrateurs et sédentaires de truite commune (Salmo trutta L.): différenciation génétique et effet des repeuplements. Les Actes du BRG 4, 63-78.

Love, R.M., 1980. The chemical biology of fishes. American Press: London, NewYork.

McGinnity, P., Prodohl, P., Ferguson, K., Hynes, R., O’maoileidigh, N., Baker, N., Cotter, D., O’hea, B., Cooke, D., Rogan, G., Taggart, J., Cross, T., 2003. Fitness reduction and potential extinction of wild populations of Atlantic salmon, Salmo salar, as a result of interactions with escaped farm salmon. Proc. Roy. Soc. 270, 2443-2450.

Metcalfe, N.B., Valdimarsson, S.K., Morgan, I.J., 2003. The relative roles of domestication, rearing environment, prior residence and body size in deciding territorial contests between hatchery and wild juvenile salmon. J. Appl. Ecol. 40, 535-544.

Millot, S., Bégout, M.L., Chatain, B., 2009. Risk-taking behaviour variation over time in sea bass Dicentrarchus labrax: effects of day-night alternation, fish phenotypic characteristics and selection for growth. J. Fish Biol. 75, 1733-1749. Gadus morhua L., towards a potential predator. Aquac. Fish. Manag. 21, 317325.

Nordeide, J.T., Svasand, T., 1990. The behaviour of wild and reared juvenile cod, Anim. Behav. 65, 245-271.

Olla, B.L., Davis, M.W., Ryer, C.H., 1994. Behavioural deficits in hatchery-reared fish: potential effects on survival following release. Aquac. Fish. Manag. 25, 19-34.

Poteaux, C., Beaudou, D., Berrebi, P., 1998. Temporal variations of genetic introgression in stocked brown trout populations. J. Fish Biol. 53, 701-713.

Price, E.O., 1999. Behavioral development in animals undergoing domestication. Appl.

Price, E.O., 2002. Animal Domestication and Behavior. CABI Publishing, New York, 297 pp. 
Ruzzante, D.E., Doyle, R.W., 1991. Rapid behavioral changes in Medaka (Oryzias Latipes) caused by selection for competitive and non competitive growth. Evolution 45, 1936-1946.

Ruzzante, D.E., Doyle, R.W., 1993. Evolution of social behaviour in a resource-rich, structured environment: selection experiments with Medaka (Oryzias Latipes). Evolution 47, 456-470.

Salvanes, A.G.V., Braithwaite, V., 2006. The need to understand the behaviour of fish reared for mariculture or restocking. ICES J. Mar. Sci. 63, 346-354.

Schreck, C.B., Olla, B.L., Davis, M.W., 1997. Behavioural responses to stress. In: O.K. Iwama, A.D. Pickering, J.P. Sumpter, and C.B. Schreck (Eds.), Fish Stress and Health in Aquaculture. Society for Experimental Biology, Cambridge, 145-170.

Serra, E., Medalha, C.C., Mattioli, R., 1999. Natural preference of zebrafish (Danio rerio) for a dark environment. Braz. J. Med. Biol. Res. 32, 1551-1553.

Steenbergen, P.J., Richardson, M.K., Champagne, D.L., 2011a. Patterns of avoidance behaviours in the light/dark preference test in young juvenile zebrafish: A pharmacological study. Behav. Brain Res. 222, 15-25.

Steenbergen, P.J., Richardson, M.K., Champagne, D.L., 2011b. The use of the zebrafish model in stress research. Prog. Neuropsychopharmacol. Biol. Psychiatry 35, 1432-1451.

Swain, D.P., Riddell, B.E., 1990. Variation in agonistic behaviour between newly emerged juveniles from hatchery and wild populations of Coho salmon Oncorhynchus kisutch. Can. J. Fish. Aquat. Sci. 47, 566-571.

Vandeputte, M., Prunet, P., 2002. Génétique et adaptation chez les poissons : domestication, résistance au stress et adaptation aux conditions de milieu. INRA Prod. Anim. 15, 365-371. and Morphological Differentiation Between Wild and Laboratory Zebrafish (Danio rerio). Behav. Genet. 36, 271-284. 
Table 1. Half-factorial design features: numbers of male and female brown trout used.

\begin{tabular}{|c|c|c|c|c|}
\hline & \multicolumn{2}{|c|}{13 Captive Fier + x 9 captive Fier $\widehat{\partial}$} & \multicolumn{2}{|c|}{13 captive Fier $q$ x 10 INRA $\widehat{\diamond}$} \\
\hline & {$[\mathrm{WxW}]_{1}$} & {$[\mathrm{WxW}]_{2}$} & {$[\mathrm{WxD}]_{1}$} & {$[\mathrm{WxD}]_{2}$} \\
\hline Fertilisation & 500 & 500 & 350 & 350 \\
\hline Day 180 & $358(0.062)$ & $336(0.155)$ & $302(0.199)$ & $204(0.091)$ \\
\hline Day 220 & 150 & 150 & 150 & 150 \\
\hline
\end{tabular}

593 Replicate sizes at fertilisation; from day 180 to day 220, replicate sizes were adjusted to 150.

594 In brackets: mean individual weight (in grammes) on day 180. W: wild captive Fier 595 (Mediterranean lineage); D: the domesticated INRA synthetic strain.

\section{Figure captions}

604 L1: 30 min in normal light conditions; D: 5 min in dark conditions; L2: 30 min in normal 605 light conditions. $P<0.05$, ***: $P<0.001$.

606

607 Figure 2. Mean \pm SEM. Swimming variables in WD and WW fish during three sequences:

608 L1: 30 min in normal light conditions; D: 5 min in dark conditions; L2: 30 min in normal 609 light conditions. Data are given for each minute. 

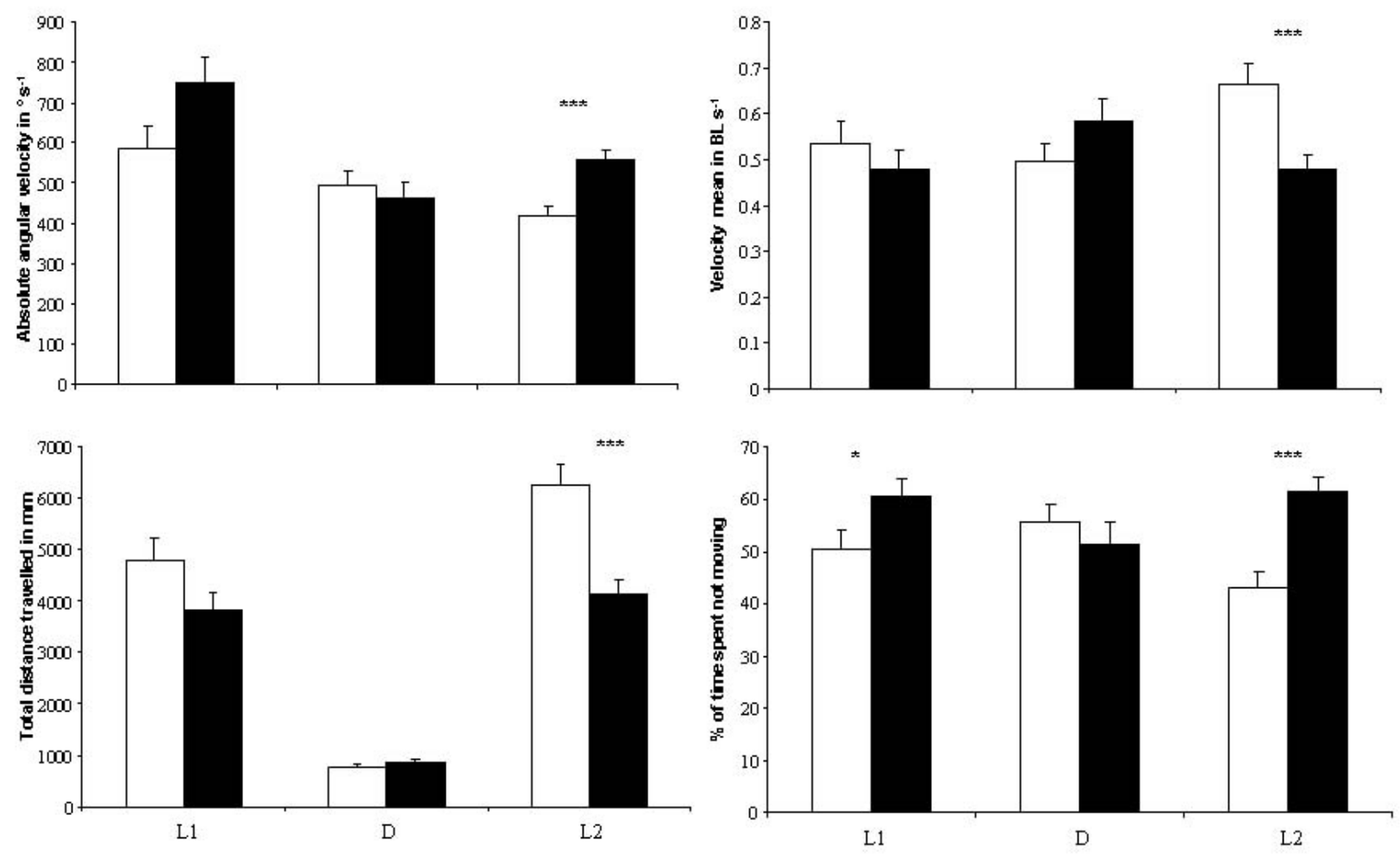

610

611

612

613

614

615 

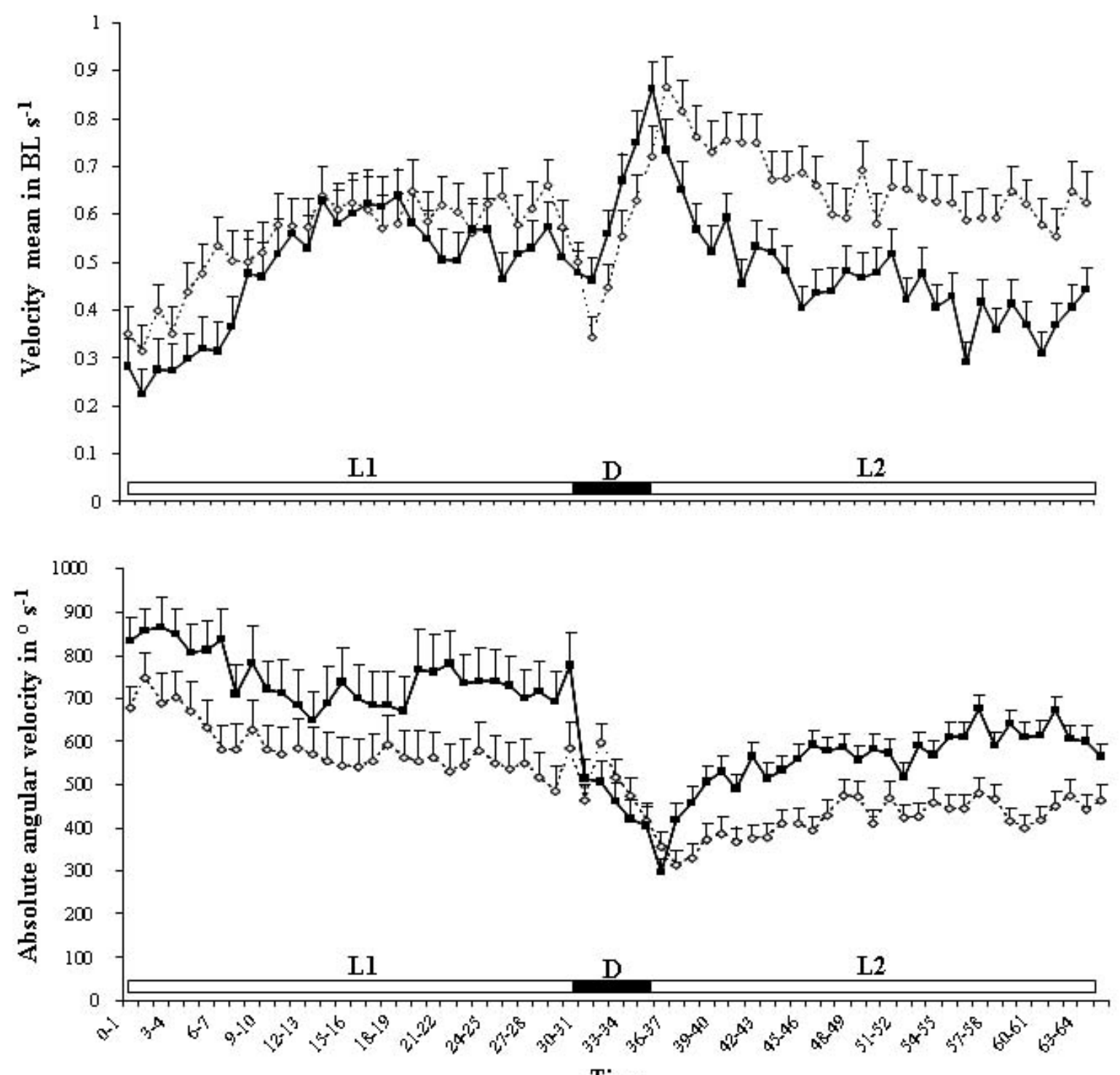

616

617

618 